\title{
Cultura, História, valores patrimoniais e museus*
}

\author{
Culture, Histoire, valeurs \\ patrimoniales et musées ${ }^{* *}$
}

Culture, History, patrimony and museums

\author{
DOMINIQUE POULOT \\ Université Paris 1 Panthéon-Sorbonne \\ Université Paris 1 Panthéon-Sorbonne, Edifício InhA \\ 2 rue Vivienne. 75002 . Paris \\ dominique.poulot@univ-paris1.fr
}

RESUMO A partir do final do século XVIII até o início da era das nacionalidades, a história dos museus está intimamente ligada à história dos edifícios patrimoniais. O apelo ao nacionalismo popular deu ênfase à formação de coleções capazes de retornar às origens coletivas da nova comunidade imaginária. O museu de história pretende, então, servir de oficina aos historiadores e de espelho de um mundo desaparecido que é necessário reivindicar e também encarnar de maneira convincente. As contradições desses objetivos e dessas abordagens tornaram-se evidentes durante 0 século XX, alimentando-se das interpretações opostas sobre o papel do museu como lugar de manipulação de patrimônios.

* Artigo recebido em: 15/07/2011. Autor convidado.

** Texto traduzido por Clara Furtado Lins. 
Palavras-chave patrimônio, museu, história, lugar de memória, construção nacional

RESUME L'histoire des musées est intimement liée à celle des constructions patrimoniales, à partir de la fin du XVIIlème siècle et du début de l'âge des nationalités. L'appel à des incarnations populaires du national conduit à mettre l'accent sur des collections capables de renvoyer aux origines collectives de la nouvelle communauté imaginaire. Le musée d'histoire entend alors servir d'atelier à l'historien et de miroir à un monde disparu dont il convient de se réclamer, et qu'on a besoin d'incarner de manière convaincante. Les contradictions des objectifs et des démarches sont devenues évidentes au cours du XXème siècle, nourrissant des lectures opposées du rôle du musée comme de la manipulation des patrimoines.

Mots clés patrimoine, musée, histoire, lieux de memoire, construction nationale

ABSTRACT From the end of the eighteenth century until the beginning of the age of nationalities, the history of museums is linked to the history of the patriotic constructions. The appeal to the popular nationalism emphasized the formation of collections able to return to the collective origins of the imagined community. The history museum is willing to serve as a workshop to the historians and as a mirror to a disappeared world that needs to be claimed and that needs to be embodied convincingly. The contradictions between these objectives and approaches became evident during the twentieth century, nurturing from the opposites interpretations of the role of the museum as a place of manipulation of patrimony.

Keywords patrimony, museum, History, memory, national heritage

Na história europeia, o significado de um patrimônio se identifica largamente com a tradição da literatura artística e, muito precocemente, congregou artistas e artesãos renomados voltados para a criação de um território e de um repertório de seus monumentos, de suas coleções e de suas obras-primas. ${ }^{1}$ A glória do príncipe, a qualidade de uma população estão, portanto, ligadas a um conjunto de considerações históricas e de julgamentos de valor estético. Essa é a definição clássica de patrimônio como desejo de ilustrar a glória da cidade - Roma, com os fundos do Capitólio,

1 SCHLOSSER, Julius von. La littérature artistique (1924). Préf. André Chastel. Paris: Flammarion, 1984. 
e depois com as coleções históricas humanistas é o melhor exemplo. ${ }^{2}$ Nos séculos XVII e XVIII, o patrimônio local alimentou a curiosidade diversificada dos antiquários direcionada mais aos utensílios, às pedras gravadas e aos figurinos do que aos seus costumes. ${ }^{3}$

\section{A inteligência material do passado}

Se aceitarmos que o nascimento da história é ligado ao "domínio do antiquado sobre o historiador", ${ }^{4}$ tem-se aqui desenhada a relação progressiva entre os objetos do cotidiano, caros ao antiquário do Antigo Regime - ou as obras de arte que ocupam o expert -, e a história tal qual ela foi construída enquanto literatura acadêmica. Durante o século XVIII, o desenvolvimento da ciência dos antiquários ou colecionadores fortaleceu as ligações entre o patriotismo e as pesquisas artísticas ou arqueológicas: os diferentes estados italianos se comprometeram a proteger seus tesouros das vicissitudes do mercado, numa tomada de consciência posteriormente julgada como se fundada pela Itália unida. ${ }^{5}$ Em outros locais, o mito céltico, ou druida, informa o olhar sobre as pedras levantadas e os cultos primitivos, às vezes conjugando-os às tentativas de decifrar as práticas populares: este é o negócio da Academia Céltica instalada no museu dos monumentos franceses sob o Primeiro Império, em que Michelet fez do incipit ${ }^{6}$ sua vocação, identificando-o a uma ressurreição do passado. ${ }^{7}$ A partir deste episódio emblemático, a museografia da história foi definida pela capacidade de trazer de volta, de maneira fiel, o passado para o presente - e, simultaneamente, de garantir a verdade de uma narrativa inteligível.

Logo após a Revolução Francesa, a questão do patrimônio tornou-se crucial. A década de 1790 e, sobretudo, a seguinte trazem, de fato, um conjunto de destruições "vândalas" como efeito indireto dos confiscos e dos realocamentos de propriedades, da liquidação de um bom número de heranças anteriormente mantidas pela Igreja ou pelas famílias aristocráticas. Elas provocam uma série de apreensões e anexações de obras de arte antigas e modernas, em favor do Louvre e dos museus da província francesa, graças ao Tratado de Tolentino e a uma mudança geral no mercado

2 FINDLEN, Paula. The museum: its classical etymology and renaissance genealogy. Journal of the History of Collections, Oxford, n.1, p.59-78, 1989

3 IMPEY, Oliver e MACGREGOR, Arthur. The origins of museums. The cabinet of curiosities in sixteenth-and seventeenth-century Europe. Oxford: Clarendon Press, 1985; POULOT, Dominique. Une histoire du patrimoine en Occident. Paris: PuF, 2006; POULOT, Dominique. Une histoire des musées de France. La Découverte, 2008; POULOT, Dominique e BALLÉ, Catherine. Musées en Europe: une mutation inachevée. Paris: La Documentation française, 2004.

4 MOMIGLIANO, Arnaldo. L'Histoire ancienne et l'antiquaire (1950). In: Problèmes d'historiographie ancienne et moderne. Paris: Gallimard, 1983, p.244-293

5 HASKELL, F. La dispersione e la conservazione del patrimonio artistico. In: Storia dell'arte italiana. Torino: Einaudi, v.12, t.III, 1981, p.5-35; HASKELL, F. L'historien et les images. Paris: Gallimard, 1995.

6 NT: Incipit: primeiras palavras de uma obra. Em latim: começo.

7 POULOT, Dominique. Musée, nation, patrimoine, 1789-1815. Paris: Gallimard, Bibliothèque des Histoires, 1997. 
de arte, que tiveram peso considerável e duradouro sobre a fisionomia das coleções públicas e privadas. A restauração do Antigo Regime em todo o continente após a queda de Napoleão não assegurou um retorno à situação anterior, em razão das muitas transformações ocorridas no tecido social: destruir o patrimônio passou a ser uma questão ideológica na luta entre a tradição e o progresso.

A oposição inédita entre o patrimônio da tradição e o patrimonialismo moderno joga com a clivagem entre o in situ e o que é desterritorializado, mas ela envolve, principalmente, várias formas diferentes de apropriação. 0 uso tradicional do patrimônio por seus habitantes e geralmente por seus "amigos" baseia-se na familiaridade da vida cotidiana e se construiu por meio dos erros de apreciação. Por outro lado, a patrimonialização moderna, ao qual o museu proporciona um lugar exemplar, se legitima largamente por meio de uma leitura esclarecida e crítica das obras e dos objetos, impondo um quadro propício ao seu reconhecimento autêntico no seio de um sistema de interpretação histórico e formal específico.

O historiador da arquitetura e filósofo estético Quatremère de Quincy sustenta que o verdadeiro patrimônio de Roma é o céu de Roma, sua paisagem de colinas, a mentalidade de seus habitantes, a música, a língua e que seus monumentos, uma vez exilados à beira do Sena, perderam todo interesse. ${ }^{8}$ Essas fórmulas desfrutaram de um reconhecimento europeu, especialmente entre os vencedores de 1815, inaugurando uma nova era do patrimônio, marcada por uma consciência melancólica da história, por uma sensibilidade inédita em relação ao patrimônio material, pela consciência, enfim, de um compromisso necessário com o lugar. Victor Hugo, Montalembert, ou Mérimée testemunharam na França o surgimento de valores que determinam um conjunto de ações públicas e individuais. ${ }^{9} \mathrm{~A}$ reflexão sobre o patrimônio agora passa a estar vinculada a uma exigência da inteligibilidade do seu contexto.

O monumento oferece, a partir da geração de 1830, um lugar de inscrição privilegiada do patrimônio e pretexto para todas as disputas de especialistas e de estetas acerca de sua restauração. Os monumentos encarnam, de fato, a fisionomia da pátria, oferecendo uma lição de história da civilização com Guizot, ou uma série de instantâneos românicos, com Walter Scott. ${ }^{10}$ Em toda a Europa, eles são recenseados e consolidados de forma concertada durante o século XIX por meio do estabelecimento de uma vigilância constante e do desenvolvimento de uma legislação específica.

8 QUINCY, Quatremère de. [1796] Lettres sur les préjudices qu'occasionnerait aux arts et à la science le déplacement des monuments de l'art de l'Itali. Whitefish: Kessinger Publishing, LLC, 2010.

9 MALLION, J. Victor Hugo et l'art architectural. Paris: Presses Universitaires de France, 1962; FERMIGIER, A. Mérimée et l'inspection des monuments historiques. In: NORA, Pierre. (dir.) Les lieux de mémoire. Paris, Gallimard Quarto, 1997, v.1, p.1599-1614.

10 POULOT, Dominique. L'archéologie de la civilisation. In: Francois Guizot et la culture politique de son temps. Colloque de la Fondation Guizot-Val Richer. Paris: Gallimard-Seuil, 1991, p.265-89. 
O culto moderno dos monumentos, reflexão encomendada pelo governo ao historiador da arte vienense Alois Riegl, tenta, no alvorecer do século seguinte, aumentar a consciência europeia do patrimônio. ${ }^{11} \mathrm{O}$ autor destaca o jogo de valores de intencionalidade, de historicidade e de antiguidade presentes nas atitudes para com os monumentos e julga que o conjunto das habilidades eruditas e dos investimentos patrióticos que determinaram as práticas vigentes no século XIX acabou, mais tarde, por ceder ao gosto sentimentalista pelo antigo, ligado às marcas de erosão do tempo inscritas sobre o monumento, ou pelo menos aos vestígios de sua ruína. Essa reflexão é tomada, simultaneamente, pela força dos valores da contemporaneidade - do gosto pelo novo - que se opõem à tradição de respeito pelo passado. A generalização do monumento antigo (isto é, "qualquer criação humana desde que demonstre claramente ter resistido ao teste do tempo", como definido por Riegl), durante o século XX, sinaliza, de fato, uma mudança maior no contexto de triunfo progressivo do individualismo de massa frente ao patrimônio.

Ainda que as políticas educativas e culturais do Estado-Providência tenham contribuído, desde a II Guerra Mundial até as últimas décadas, para o culto da herança patrimonial, a preocupação de uma pequena elite compromissada com a coletividade não será, senão, objeto de delegação. Além das questões das instituições tradicionais, o fenômeno é parte de uma mudança fundamental: a da nova definição de cultura a partir da década de 1960, incluindo agora os mais diversos aspectos das práticas sociais, no momento em que a paisagem material e imaterial passava por rápidas e aceleradas transformações. Finalmente, a atenção dirigida aos manejos políticos do passado e aos usos públicos da história revelou amplamente que o patrimônio era resultante de reconstruções com base na classificação e na escolha, bem como de esquecimentos seletivos e de comemorações voluntaristas. ${ }^{12}$

\section{Os museus entre o patrimônio e a história}

A relação entre museu e patrimônio é, por sua vez, tanto óbvia quanto paradoxal. Óbvia porque geralmente fala-se comumente de "museu perdido"13 para evocar não somente o desaparecimento de objetos e de coleções, mas também de monumentos, de castelos e de outras vítimas de inúmeros vandalismos. Na verdade, os utensílios arqueológicos e históricos são reunidos nos acervos de museus e do patrimônio nacional. Bouvard

11 RIEGL, Alois. [1903] Le culte moderne des monuments: sa nature, son origine. Paris: Paris-Villemin/École d'Architecture, 1984.

12 POIRRIER, Ph. e VADELORGE, L. (eds.) Pour une histoire des politiques du patrimoine. Paris: La Documentation française, 2003.

13 ADAMS, Robert Martin. The lost museum: glimpses of vanished originals. New York: Viking Press, 1980. 
e Pécuchet, enquanto empreendiam sua investigação sobre o passado, focaram-se primeiramente no acúmulo de objetos antigos ("eles se tornaram arqueólogos, e sua casa se parecia com um museu"), e na visita de monumentos "para, em suma, ver a história viva na praça pública". ${ }^{14}$ A estas iniciativas sucedeu-se o recurso à memória dos autores e depois um projeto de escritura da história - neste caso a biografia do duque de Angoulême. Assim, os três elementos da consciência do passado - patrimônio, memória e história - foram intimamente reunidos em seus breves percursos. No entanto, a ligação entre museus e patrimônio é, também, paradoxal, já que o patrimônio in situ é negado, ou pelo menos repetido por um outro - desterritorializado, montado em série, exposto em um contexto artificial. O museu se apega à afirmação de uma inovação intelectual que tende a se consolidar com o aumento da confiança na sua versão ocidental, concorrente - e isso não é o menor paradoxo - ao progresso contínuo da exigência de inteligência contextual no seio das ciências humanas e sociais. ${ }^{15}$

O patrimônio pretende encarnar as visões gerais da ciência, quando a nação começa a tomar "consciência de si mesma como uma nação" ${ }^{16}$ Ele reivindica ser um tipo de abertura para o futuro, ao mesmo tempo laboratório e arquivo da história - tal qual é o museu dos arquivos, inaugurado em 1867, em Paris. A este laboratório ideal é atribuído uma responsabilidade educacional: a visita ao museu contribui, paralelamente, para o ensino obrigatório e a circulação de jornais, a formação de "comunidades imaginárias", ${ }^{17}$ tanto na escala da "pequena pátria" quanto da grande..$^{18}$ Alguns museus de história acumulam bibliotecas e centros científicos, publicando e divulgando manuais - tais como o Museu Nacional Germânico, em Nuremberg (1852), ou o Ossolineum, de Lvov (1817) - a serviço da uma visão cumulativa do passado, num trabalho patriótico. ${ }^{19}$

Reproduzir a vida da mesma maneira que ela foi vivida parece responder ao ideal do historiador Leopold von Ranke, que afirmou, em 1824, que não se tratava de "julgar o passado, de formar seus contemporâneos e assim determinar o futuro", mas sim de "mostrar o que realmente se passou". ${ }^{20} \mathrm{Na}$ verdade, o museu muitas vezes leva a uma naturalização da história, quer dizer, sua mitologização (conforme definido por Roland Barthes), com simulacros cada vez mais e mais elaborados. Nos EUA, o empreendimento de Henry Ford de colecionar, por volta de 1906, a cultura material em todos

14 FARGE, Arlette. Des lieux pour l'histoire. Paris: Seuil, 1997.

15 BURKE, Peter. Context in context. Common Knowledge, Baltimpore, v.8, p. 152-177, 2002.

16 NORA, Pierre. (dir.) Les lieux de mémoire. Paris: Gallimard Quarto, v.1, 1997.

17 ANDERSON, Benedict. [1983] L'imaginaire national: réflexions sur l'origine et l'essor du nationalisme. Paris: La Découverte, 1996.

18 CHANET, Jean-François. L'école républicaine et les petites patries. Paris: Aubier, 1996.

19 BERÇÉ, Y.-M. (ed.) Archives et nations dans l'Europe du XIXe siècle. Paris: Ecole des Chartes, 2004.

20 BOUTON, Christophe. Le procès de l'histoire. Fondements et postérité de l'idéalisme historique de Hegel. Paris: J. Vrin, 2004 
os seus aspectos, tornou o Greenfield Village o maior museu a céu aberto do país, fruto de uma aversão declarada aos estudiosos de história. ${ }^{21}$ Ele queria promover "a história do nosso povo tal qual ela está escrita nas coisas que suas mãos têm fabricado e usado", numa perspectiva de retornar ao real e de repetir o passado - o que requer intérpretes fantasiados. Proposta similar se banaliza por meio de uma história "pública" ou aplicada - aquela dos centros de interpretação, ou dos museus de paisagens pitorescas. ${ }^{22}$ Além disso, algumas instituições pretendem defender uma história alternativa, trabalhando na invenção de identidades comunitárias a partir de memórias e de artefatos, denunciando o desprezo e a censura acadêmica a suas propostas. Neste sentido, a história dos historiadores e a história dos museus de história gradualmente se divergem, pleiteando legitimidades que se sobrepõem apenas parcialmente.

$\mathrm{Na}$ França, se, particularmente, a história das mentalidades encontrou, em tempo, uma fortuna exemplar no museu, é em razão daquilo que Philippe Ariès chamou de "reconciliação recente do passado com o presente", ocorrida principalmente dentro dos museus do terror ou da identidade, dos museus de etnografia regional e dos dispositivos renovados do ecomuseu. ${ }^{23}$ Na prática dos museus de sociedade da década de 1980, a imersão nas práticas do passado, longe de ser nostálgica, deve "despertar para os problemas do presente", segundo a Federação de Ecomuseus. ${ }^{24} \mathrm{O}$ ecomuseu, ou museu da sociedade, pretende desenvolver uma nova representação do patrimônio nacional concebida como tomada de consciência dele mesmo pela sociedade, graças à descoberta (interminável) de suas propriedades. Segundo Freddy Raphael, ele configura "uma provocação da memória" de um modo voluntarista, que deve ressuscitar ou fazer ressurgir antigos hábitos. ${ }^{25}$ Trata-se menos de contribuir com esta comunhão nacional para o luto evocado por Renan, em O que é uma Nação?, de 1882, do que de compartilhar uma experiência da vida passada, que encontra sua lógica no consumo, na loja de produtos novos mas "de época".

Tal é o caso ainda dos novos museus de história, de arquitetura manifestadamente simbólica, que participam de uma perspectiva comemorativa, ou que querem acabar com uma guerra de memórias: esses devem sua abertura à vontade política de colocar certas lembranças no primeiro plano da consciência coletiva, no caso de uma pacificação, ou de uma reconci-

21 CARSON, Cary. Colonial Williamsburg and the practice of interpretive planning in American history museums. The Public Historian, California, v.20, n.3, p.11-51, Summer, 1998.

22 RENTZHOG, Sten. Open air museums: the history and future of a visionary idea. Stockholm: Carlssons Jamtli Förlag, 2007.

23 ARIĖS, Philipe. Histoire des mentalités. In: LE GOFF, Jacques. (dir.) La Nouvelle Histoire (1978). Bruxelles: Editions Complexe, 2006.

24 Ecomusées en France. Premières rencontres nationales des écomusées. Grenoble: Ecomusée Nord-Dauphiné, 1987

25 RAPHAËL, Freddy. Le musée, provocation de la mémoire. Ethnologie Française, Nanterre, v.17, n. 1, p.87-94, 1987. (avec Herberich-Marx G.) 
liação - de toda maneira é um processo de transição. Repousando sobre a colaboração com os movimentos políticos e sociais, guardiões da memória há pouco tempo censurados, os museus favorecem o trabalho de luto de uma maneira que é ao mesmo tempo familiar e assustadora, segundo a fórmula do Museu do Apartheid, em Joanesburgo. ${ }^{26}$ Em tal projeto, o museu se atém a uma verdade do passado enraizada no presente, em termos de memórias e valores consagrados nos debates políticos e civis.

\section{As coleções e as relações sociais hoje}

O museólogo norte-americano Stephen Weil diagnosticou, pouco antes da virada do milênio, o triunfo de uma museologia relacional, construída sobre os valores do público ou da comunidade a que se destina. ${ }^{27}$ Uma das questões centrais da história cultural do patrimônio é saber como negociar entre o antigo regime dos objetos de memória e suas novas civilidades e seus novos atributos. ${ }^{28}$ Muitos dos amigos de objetos parecem despossuídos, materialmente e simbolicamente, de suas disposições individuais em relação à experiência histórica quando se elabora, pela primeira vez, um movimento coletivo dedicado ao patrimônio e, em seguida, às recomposições pessoais e comunitárias de suas várias funções. ${ }^{29}$ No sentido inverso, diferentes modos de viver o acervo patrimonial coexistem em cada momento: um tal objeto, que se reveste de uma intensa patrimonialização pública, e um outro, que participa de uma idiossincrasia, podem mudar suas posições em função de identidades móveis. ${ }^{30}$

As formas de apropriação passam por diferentes graus de intimidade social com o passado material, bem como pela distribuição desigual da "grandeza" - entre coleções e museus. ${ }^{31} \mathrm{O}$ tema do privado - este, por sua vez, reflexo das paixões privadas do colecionador ou do homem de ciências e estabelecido a partir dos registros de habitações, de ocupações - está amplamente representado em museus e no arranjo patrimonial, dando lugar às formas de sociabilidade mais ou menos alargadas, do círculo fechado dos amadores ao ativismo associativo. ${ }^{32} \mathrm{O}$ amador e o perito são, hoje em dia, duas figuras notórias da nova história dos patrimônios como da dos

26 FASSIN, D. Ce qui s'est vraiment passé. L'expérience du musée de l'Apartheid. Gradhiva, Paris, n.5, p.52-61, 2007.

27 WEIL, Stephen E. From being about something to being for somebody: the ongoing transformation of the American museum. Daedalus, Cambridge, v.128, n.3, p.229-258, 1999.

28 DEBARY, Octave e TURGEON, Laurier. (eds.) Objets et mémoires. Paris: Éditions de la Maison des Sciences de l'Homme, 2007.

29 CRANE, Susan. (ed.) Museums and memory. Stanford: Stanford University Press, 2000.

30 FABRE, Daniel e IUSO, Anna. (eds.) Les monuments sont habités. Paris: Éditions de la Maison des Sciences de l'Homme, Coll. Cahiers d'ethnologie de la France, n.24, 2009.

31 WRIGHT, Gwendolyn. (ed.) The formation of national collections of art and archaeology. Washington, DC: National Gallery of Art, 1996; COOMBES, Annie E. Museums and the formation of national and cultural identities. The Oxford Art Journal, Oxford, v.11, n.2, p.58-68, 1988.

32 VOLAIT, Mercedes. Fous du Caire: excentriques et amateurs d'art islamique en Égypte (1867-1914). Apt: L'Archange Minotaure, 2009. 
saberes ou do divertimento. ${ }^{33}$ Os amigos dos objetos patrimoniais, quer sejam eles amadores ou profissionais, polígrafos ou especialistas, militantes ou funcionários, que se constituem em comunidades de interpretação ou de diálogo científico, estabelecem-se como porta-vozes das inovações, das apropriações e das citações. ${ }^{34}$ Algumas dessas figuras - 0 antiquário e sua ruína, o conservador e seu museu, o folclorista e seu campo - são passados, pouco a pouco, ao estado de quase-estereótipos antropológicos, para além de clichés literários. ${ }^{35}$

A questão do patrimônio suscitou uma tipologia de objetos cujo leque está, de forma constante, em contínuo aumento, como se ela respondesse a um repertório universal no qual assume a inclinação do momento. Nesse sentido, o jornalismo patrimonial, se se pode chamá-lo assim, periodicamente anunciando invenções e descobertas, trabalha para ajustar um sentido de passado e a consciência do presente - contribuindo de forma significativa para normalizar as diferenças que se colocam para enxergar as singularidades. Enquanto isso, a emergência e a posterior ascensão de um conjunto de saberes técnicos - de uma economia de coleção de objetos à valorização dos museus e de sua gestão - tornaram-se elementos chave da esfera patrimonial. Para além da diversidade de objetos que devem ser adotados, conservados, tratados, as inúmeras maneiras como as coisas se tornam objetos apropriados para se pensar, entre a reivindicação patrimonial e o saber histórico, alimenta hoje uma história das emoções e das memórias. ${ }^{36}$ Se a maioria das análises críticas dos últimos anos passou a ver nos museus um empreendimento canibal, ${ }^{37}$ mais recentemente, uma versão mais positiva pretende reconhecer neles sua função de lugar de mudança entre recursos das culturas. ${ }^{38} \mathrm{~A}$ metáfora de área de contato está a caminho de dominar as representações contemporâneas do museu, ao mesmo tempo que a noção de cosmopolitismo torna-se central.

À sua maneira, estes dois discursos parecem responder às exigências normativas que Arjun Appadurai aponta, quando ele vê o passado como um recurso raro, e não como um material disponível a qualquer manipulação - ideia que está no cerne de muitas análises sobre o patrimônio, que destacam sua plasticidade quase infinita e sua indiferença em relação à

33 GUICHARD, Charlote. Les amateurs d'art à Paris au XVIIle siècle. Seyssel: Éditions Champ Vallon, 2008; GUICHARD, Charlote. Du 'nouveau connoisseurship' à l'histoire de l'art. Original et autographie en peinture. Annales. Histoire, Sciences sociales, Paris, n.6, p.1387-1402, 2010; GUICHARD, Charlote. Les formes de l'expertise artistique en Europe. Revue de Synthèse, Paris, n.1, 2011.

34 TAMEN, Miguel. Friends of interpretable objects. Cambridge: Harvard University Press, 2001.

35 POULOT, Dominique. Histoire du patrimoine: bilan et perspectives. In: BOUDIA, Soraya ; RASMUSSEN, Anne e SOUBIRAN, Sébastien. (dirs.) Patrimoine et communautés savantes. Rennes: PUR, 2010, p.25-47.

36 ROSENWEIN, Barbara H. Worrying about emotions in history. American Historical Review, Indiana, n.107 p.821-845, June 2002.

37 GONSETH, Marc-Olivier, HAINARD, Jacques e Kaehr Roland. (dirs.) Le musee cannibale. Neuchâtel: Musée d'Ethnographie, 2002.

38 CLIFFORD, James. Museums as contact zones. In: Routes: travel and translation in the late twentieth century. Cambridge: Harvard University Press, 1997. 
verdade. ${ }^{39}$ Arjun Appadurai isola a este respeito quatro dimensões, que desenham a estrutura universal minimalista da construção dos passados: a autoridade, ou o acordo sobre a credibilidade; a continuidade, ou o benefício da fonte de autoridade; a profundidade, ou a avaliação do fortalecimento no passado; enfim a interdependência, ou seja, a verossimilhança entre as diferentes versões do passado. Um passado compartilhado em comum existe, mas grupos diferentes podem reivindicar uma parte dele, ou acentuarem um ou outro aspecto em particular, entre um tempo ritual, sem duração, e o tempo do mundo, dominado pelo presente que passa. ${ }^{40} \mathrm{O}$ museu representa, desse ponto de vista, um dos dispositivos que aloja o passado nos recursos do presente - de uma maneira mais ou menos em consonância com os direitos exercidos sobre um patrimônio.

39 LOWENTHAL, David. Possessed by the past: the heritage crusade and the spoils of History. Free Press, 1996, p.128: "A história conta a todos o que aconteceu e como as coisas se tornaram o que são. O patrimônio transmite os mitos exclusivos de origem e de continuidade, e dota um grupo escolhido de prestígio e perspectivas comuns (...) A história é para todos, o patrimônio é apenas para nós mesmos (...) O patrimônio nos faz retornar às regras tribais que fazem de cada passado uma propriedade exclusiva, secreta. Criado para gerar e proteger os interesses dos grupos, ele os beneficia apenas se for recusado aos outros (...) Nós exaltamos nosso próprio patrimônio, não porque ele revela uma evidência demonstrável, mas porque ele deve ser verdadeiro". (tradução a partir de versão do autor).

40 "O passado constitui uma modalidade discursiva alternativa em si mesmo de outros modos de comunicação cultural, que podem assumir um eterno presente e que, muitas vezes, se situam de fato nesse quadro temporal. As normas do discurso sobre o passado desenham um campo da cultura que pode fazer concessões à mudança e reconhecer a divisão e o debate. Em suma, essas normas autorizam novas formas de ação, ao mesmo tempo que permitem que as culturas regulem sua mudança social". APPADURAI, Arjun. The social life of things: commodities in cultural perspective. Cambridge: Cambridge University Press, 1981, p.218. (tradução a partir de versão do autor). 